\author{
REVISTA ELETRÔNICA \\ DA GRADUAÇÃO/PÓS-GRADUAÇÃ̃ EM EDUCAÇÃO \\ UFG/REJ
}

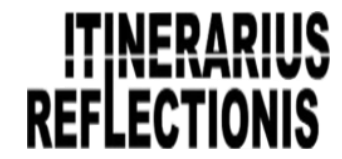

ISSN. 1807-9342

Volume 14, N. 2, 2018

\title{
GEOGRAFIA HUMANISTA, HETEROTOPIA E POLIVOCALIDADE novos percursos para o ensinar-aprender
}

\begin{abstract}
Rodrigo Capelle Suess ${ }^{1}$
Resumo: Este trabalho tem como objetivo identificar e explorar algumas temáticas e metodologias do horizonte humanista que possibilitam novos caminhos para o ensino de Geografia. A polivocalidade de temas abertos à ciência geográfica, especialmente, após a década de 1970, é um legado do horizonte humanista ou abordagem cultural em Geografia. Perspectiva que se pauta nas filosofias dos significados, particularmente, na fenomenologia. Trata-se de desvelar novos percursos e olhares para o ensino de Geografia, ainda poucos explorados pelos geógrafos humanistas. Para isso, utilizou-se de pesquisas bibliográficas de diversos autores desse horizonte e da Geografia escolar, além de algumas de minhas reflexões e investigações que vão ao encontro dessas temáticas.
\end{abstract}

Palavras-chave: Geografia humanista. Experiência docente. Metodologias e temas do ensino de Geografia.

\section{HUMANIST GEOGRAPHY, HETEROTOPIA AND POLIVOCALITY new pathways to teach-learn}

\begin{abstract}
This work has as objective identify and explore some thematic and methodologies of the humanist horizon that make possible new paths for the teaching of Geography. The polyvocality of themes open to geographic science, especially, after the 1970s, is a legacy of the Humanist Horizon or Cultural Approach in Geography. Perspective that is based on the philosophies of meanings, particularly, in phenomenology. It is about unveiling new paths and looks for the teaching of Geography, still few explored by humanist geographers. For this, we used bibliographical research of several authors of this horizon and the School Geography, plus some of my reflections and investigations that meet these thematic.
\end{abstract}

Keywords: Humanist geography. Teaching experience. Methodologies and themes of Geography teaching.

\section{PALAVRAS INICIAIS}

Sabe-se, como já defendido em Suess (2016), que os horizontes epistemológicos da Geografia, positivista, crítico e humanista, especialmente, esse último têm muito a contribuir para o processo de ensino-aprendizagem, principalmente quando se visa a formação de um indivíduo que conhece a si mesmo - o seu corpo, o seu espaço, o seu tempo e os significados dado a cada um desses - e o mundo. Por isso, um indivíduo que

\footnotetext{
${ }^{1}$ Doutorando e Mestre em Geografia pela Universidade de Brasília (UnB). Professor da Carreira do Magistério Público da Secretaria de Estado de Educação do Distrito Federal - SEEDF. Integra o grupo de pesquisa - Ensino, Aprendizagem e Formação de Professores em Geografia da Universidade de Brasília GEAF/UnB. E-mail: rodrigo.capellesuess@gmail.com
} 


\section{REVISTA ELETRÔNICA \\ DA GRADUAÇÃO/PÓS-GRADUAÇÃO EM EDUCAÇÃO \\ UFG/REJ}

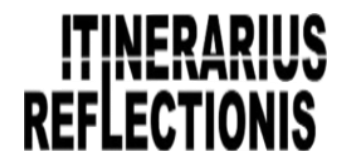

ISSN. 1807-9342

Volume 14, N. 2, 2018

incorpora essas informações em prol da construção de uma cidadania em conjunto com o outro. "Um geografia efetivamente humana é uma geografia humana crítica e relevante, que pode contribuir para o próprio núcleo de uma educação humanista: melhor conhecimento e compreensão de nós mesmos, dos outros e do mundo que compartilhamos" (COSGROVE, 2012, p. 236).

Esse horizonte se tornou revolucionário no âmbito da ciência geográfica, não apenas por ir de encontro a um fazer nomotético e numérico, predominante em boa parte das ciências humanas no pós Segunda Guerra, mas por resgatar algo que até mesmo a Geografia Crítica ao bater de frente e (re)construir um novo modo ou um novo sentido aos métodos e temas então apropriados não fez, trata-se da ruptura com as "verdades" das ciências modernas, que abriu espaço para o mundo da vida e uma gama de estudos que consideram as intenções humanas.

Com isso, o horizonte humanista se predispôs a ir além do conhecimento científico, ao englobar e considera aquilo que o Horizonte positivista e até mesmo o Horizonte Crítico consideraram como metafísico, como saberes menores, alienados, desnecessários. A partir daí, a polivocalidade de temas abertos a ciência geográfica é um legado do Horizonte humanista ou Abordagem em Geografia, pautados nas filosofias dos significados, particularmente, a fenomenologia.

Cabe ressaltar, que o ir além, exposto a cima, não significa desconsiderar, menosprezar, ou apequenar os saberes científicos, mas trabalhar com eles e com outras formas de saberes, como a Arte, a Filosofia, a Literatura e até mesmo o que é de conhecimento popular. Trata-se, como defende Freire e Guimarães (2011), de utilizar a metodologia científica para se aproximar dos fatos reais e melhor entendê-los. Para isso, deve-se constituir uma Geografia que não segrega o cognitivo e tudo aquilo que pertence a vida, como as artes, emoções e desejos. Trata-se de assumirmos uma Geografia que leva em conta o ser humano em sua totalidade, sem dicotomizar aquilo que é ciência e aquilo que não é. "Não há saber mais, nem saber menos, há saberes diferentes" FREIRE, 2014a, p.68). Desse modo, a ciência para o horizonte humanista em Geografia, encontra-se mais para a busca da cientificidade do que para o cientificismo, como muitos outros horizontes, em momentos diferentes, buscaram.

Acreditamos que essa perspectiva, assim como as outras, tem a sua contribuição para um projeto de ensino em Geografia, pois seus ensinamentos podem resultar em uma 


\section{REVISTA ELETRÔNICA \\ DA GRADUAÇÃO/PÓS-GRADUAÇÃO EM EDUCAÇÃO \\ UFG/REJ}

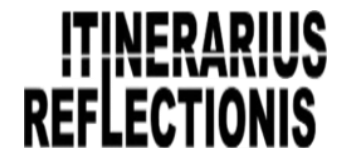

ISSN. 1807-9342

Volume 14, N. 2, 2018

nova forma de pensar o conhecimento geográfico, um novo olhar como o professor pode ensinar, nas formas que o aluno pode aprender e, principalmente, na construção de um projeto de sociedade e uma nova experiência espacial que esse saber, mediado pelo professor, pode ajudar a construir.

Confiamos que a filosofia e os saberes desse horizonte possam forjar um novo comportamento ético no professor, o que chamaremos aqui de uma atitude ou postura humanista no ensino de Geografia. Isto significa, que essa atitude objetiva valorizar o sujeito humano e toda sua amálgama de possibilidades para elevar a construção de conhecimentos em Geografia que resulte em um aluno ciente de si, do outro e do mundo em que vive.

Dessa maneira, essa perspectiva, em nível escolar, pode ser empregada para melhoria do processo de ensino-aprendizagem, pois imputa à reflexão e ação sobre o ensinar/aprender, o que ensinar-aprender, o como ensinar-aprender, qual é a finalidade desse ensinar-aprender, pautada na subjetividade dos sujeitos envolvidos na relação de ensino-aprendizagem, num determinado lugar e momento de mundo. Por isso, possibilita um ensino de Geografia que oriente à cidadania e a compreensão do mundo vivido.

Assim, sabendo dessas múltiplas potencialidades, algumas bem exploradas em Suess (2016), temos como objetivo principal, nesse trabalho, identificar e explorar algumas temáticas e metodologias do horizonte humanista que possibilitam novos caminhos para o ensino de Geografia. Trata-se de um ensaio propositivo, portanto, não conclusivo e aberto a inclusões ou até mesmo refutações. Para isso, utilizou-se de pesquisas bibliográficas de diversos autores do horizonte humanista em Geografia e, igualmente, da Geografia Escolar, além de algumas de minhas reflexões e investigações que vão ao encontro da temática realizadas no decorrer de minha trajetória acadêmica.

\section{O QUE É O HORIZONTE HUMANISTA EM GEOGRAFIA?}

A Geografia humanista e a Geografia cultural renovada constituem campos muito próximos um do outro, e por isso possuem imbricações. Existem vários pontos comuns entre essas duas abordagens, desde o contexto histórico, temáticas de estudo, e o uso da fenomenologia, o que faz ambas constituírem um campo teórico, que compartilha dos mesmos autores e de algumas ideias. "[...] Os autores conhecidos como de uma abordagem são utilizados amplamente pela outra, [...] sendo frequentemente 


\section{REVISTA ELETRÔNICA \\ DA GRADUAÇÃO/PÓS-GRADUAÇÃO EM EDUCAÇÃO \\ UFG/REJ}

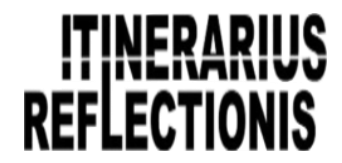

ISSN. 1807-9342

Volume 14, N. 2, 2018

'confundidos', encontramos às vezes um autor sendo considerado pertencente às duas correntes e sua obra sendo declarada base para ambas" (MARANDOLA JR., 2005).

A Geografia cultural e a Geografia humanista, denominadas de abordagem cultural por Claval (2002), leva Gomes (2000) a considerar que tal vinculação integra um novo horizonte, o terceiro no contexto epistemológico da Geografia: o humanista. Desse modo, compõe juntamente com o horizonte neopositivista e com o horizonte marxista o universo epistemológico dessa ciência. O horizonte humanista pode ser visto também por outros autores como um fundamento interpretativo dos valores, ligados às filosofias dos significados, em especial, à fenomenologia (MARANDOLA JR., 2013; MONTEIRO, 2002; MOREIRA, 2014).

Trata-se de uma nova geografia, focalizada nas subjetividades das ações culturais humanas, capaz de possibilitar "di un'interpretazione dei vari paesaggi, territori o luoghi, che non fosse solo "oggettiva"ma avesse anche un contenuto profondamente culturale, soggettivo o, meglio, psicologico" (LANDO, 2012, p. 264).

Como evidencia Mello (1990), a Geografia humanista constitui-se uma alternativa aos estudos geográficos, que tem como tarefa a interpretação da dinâmica da experiência vivida, a consideração dos sentimentos e entendimento do homem sobre o espaço e o lugar. Nesse sentido, não deseja estabelecer uma única verdade, não almeja explicar o mundo por uma única e acabada teoria, dispensa hipóteses e pressuposições. Ao contrário, centraliza o homem enquanto ser pensante, indaga sobre a simbologia que envolve os lugares das pessoas e como esse significado afeta a organização espacial (MELLO, 1990).

Uma geografia permeada por valores humanistas visa tornar esse saber em uma meditação, em um espaço de reflexão e sabedoria, em um relatório sensível, no qual a intuição não é ignorada. Uma geografia capaz de fazer narrativas, que sejam capazes de elucidar a experiência particular de cada homem, com relação aos seus redutos e territórios. Para isso é necessário reconhecer que essa análise implica degrades do real e do imaginário e, muitas vezes, acabam denunciando o que não é aceitável (BAILLY; SCARIATI, 2001, p. 214). Talvez, seja por isso que, devemos considerar, não apenas

\footnotetext{
2 [...] uma interpretação das várias paisagens, territórios e lugares que não fosse somente "objetiva" mas tivesse também um conteúdo profundamente cultural, subjetivo ou, melhor, psicológico (LANDO, 2012, p. 264 , tradução nossa).
} 


\section{REVISTA ELETRÔNICA \\ DA GRADUAÇÃO/PÓS-GRADUAÇÃO EM EDUCAÇÃO \\ UFG/REJ}

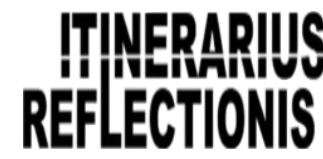

ISSN. 1807-9342

Volume 14, N. 2, 2018

como um momento, como defendeu Lévy (1981), mas como um continuum de esperança em Geografia.

POLIVOCALIDADE E HETEROTOPIA: uma contribuição ao Ensino de Geografia

Por meio de sua renovação, especialmente, na década de 1970, em oposição a uma abordagem cultural clássica, esse horizonte tornou-se aberto, transformou-se numa heterotopia, sujeito à polivocalidade, o que significou uma pluralidade de caminhos e aproximações (CORRÊA e ROSENDAHL, 2012a). Por polivocalidade, Corrêa e Rosendahl (2012) a considera como um antídoto contra a imposição de um único significado, geralmente forjado pelas elites, como imposição de sua hegemonia cultural. "A geografia cultural beneficiou-se com aportes do marxismo, da fenomenologia, da hermenêutica, das ciências sociais e humanidades, como a crítica literária e a linguística, e das ciências naturais" (CORRÊA e ROSENDAHL, 2012, p. 90).

Portanto, trata-se de uma geografia que abre espaços para os lugares de diferenças, para os espaços não-hegemônicos, compostos por múltiplos significados, diversos sujeitos, vários tempos e espacialidades. Essa diversidade temática revolucionou o modo de fazer e conhecer a Geografia. No ensino de Geografia ainda é um campo pouco explorado e bem fértil, algumas propostas de aplicação serão apresentadas.

Antes de partirmos, especificamente, para alguns recortes ou aberturas de temas, consideramos de extrema importância, destacar, a interdisciplinariedade como eixo estruturante do horizonte humanista, característica que somada a outras ideias do projeto filosófico e espistemológico desse novo movimento, justificam o aparecimento de múltiplas possibilidades temáticas.

A interdisciplinariedade, ou como menciona Bailly e Scariati (2001), a multidisciplinaridade, sobretudo, com outros campos das ciências humanas vêm permitindo um troca positiva entre a Geografia e essas ciências. Ao comparar a interdisciplinaridade com o movimentos de duas ou mais ondas, Barros (2017, p. 10) ressalta que, "um encontro entre duas ondas não pode ocorrer sem que as duas partes efetivamente se transformem; e sem que, de alguma maneira, o próprio oceano, vasta extensão agitada por muitas ondas, também se transfigure". 


\section{REVISTA ELETRÔNICA \\ DA GRADUAÇÃO/PÓS-GRADUAÇÃO EM EDUCAÇÃO \\ UFG/REJ}

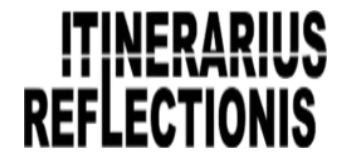

ISSN. 1807-9342

Volume 14, N. 2, 2018

Nesse encontro de ondas propostos pela Geografia humanista com a Entologia, Antropologia, Filosofia, Psicologia, Sociologia, História e com as Artes ela sai beneficiada e beneficia discussões temáticas que a partir de então passam a ser compartilhadas entre dois ou mais saberes. Desse modo, são essas novas temáticas, ora resgatadas ou descobertas pela relação com outras ciências, ora (re)construídas a partir de um novo olhar sobre o espaço geográfico, que atentamos com intuito de contribuir para o processo de ensino-aprendizagem que acontece em Geografia.

A reinvididação de diversos grupos e movimentos sociais que não aceitam apenas serem diferenciados por meio da dicotomia burguesia/proletariado, impulsionaram a heterotopia e polivocalidade das abordagens temáticas. Dentro dos espaços de exclusão não foram apenas os despossuídos economicamente que expuseram suas angústias, mas também os ambientalistas, as mulheres, os negros, os homossexuais, os trangêneros e outras ditadas minorias no âmbito do poder econômico, político, social e cultural. Portanto, a apropriação dos espaços de produção de conhecimentos por parte desses grupos permitiu, igualmente, um boom nas temáticas aceitáveis como campo de investigação na ciência geográfica.

O contexto e a pressão por um conceito de espaço e cultura que desse conta das aflições que se intensificaram por meio de uma nova sensibilidade do espaço-tempo, também, ampliou os campos temáticos atribuidos a Geografia. Tratou-se da superação da noção de cultura como uma entidade acima do homem, supra orgânica, em favor de uma cultura como contexto, como reflexo, meio e condição da existência das pessoas e dos grupos. Assim, a cultura entra em uma perspectiva interpretativa, composta de significados criados e recriados por grupos sociais, capaz de refletir as diversas esferas da vida e suas espacialidades. Trata-se da concepção de cultura mais utilizada pela Geografia humanista (CORRÊA e ROSENDAHL, 2011, 2012b; DUNCAN, 2011).

Cabe, então, identificamos algumas diversidades metodológicas, teóricas e temáticas resgatadas e (re)construídas pelo horizonte humanista em Geografia que podem se constituir em novos caminhos para o ensino de Geografia. Acompanhado com esses tópicos, indicaremos, por meio de quadros, algumas referências teóricas ou que refletem alguma experiência pedagógica com o assunto abordado:

- Resgate político da cultura ao apontar relações entre cultura, classes sociais, poder, políticas culturais são úteis para o entendimento do aluno do mundo capitalista e a sua 


\section{REVISTA ELETRÔNICA \\ DA GRADUAÇÃO/PÓS-GRADUAÇÃO EM EDUCAÇÃO \\ UFG/REJ}

produção de significados. Trata-se de um posicionamento crítico da homogeneização cultural e da descoberta de movimentos de resistências em um mundo dominado pela acumulação flexível do capital (Quadro 1).

Quadro 1. Algumas referências importantes a respeito do resgate político da cultura.

\begin{tabular}{|c|c|c|c|}
\hline Autor (Citação) & Título da obra & Revista/Editora & Ano \\
\hline $\begin{array}{c}\text { CORRÊA, } \\
\text { Roberto Lobato }\end{array}$ & Monumentos, política e espaço & Ed.UERJ & 2013 \\
\hline $\begin{array}{c}\text { ROSENDAHL, } \\
\text { Zeny }\end{array}$ & Espaço, política e religião & Ed. UERJ & 2013 \\
\hline $\begin{array}{c}\text { CORRÊA, } \\
\text { Roberto Lobato }\end{array}$ & Cultura, política, economia e espaço & Espaço e Cultura & 2014 \\
\hline $\begin{array}{c}\text { MOREIRA, } \\
\text { Marianna } \\
\text { Fernandes }\end{array}$ & $\begin{array}{c}\text { Casa e família na geografia: estratégias } \\
\text { espaciais de mulheres sem-teto na construção do } \\
\text { lar }\end{array}$ & Espaço e Cultura & 2013 \\
\hline $\begin{array}{c}\text { BOTELHO, } \\
\text { Maurílio Lima }\end{array}$ & $\begin{array}{c}\text { Colonialidade e forma da subjetividade } \\
\text { moderna: a violência da identificação cultural } \\
\text { na América Latina }\end{array}$ & Espaço e Cultura & 2013 \\
\hline
\end{tabular}

Elaboração: Rodrigo Capelle Suess, 2018.

- Gênero e sexualidade permitem trabalhar uma perspectiva de conhecimento do corpo e (re)construção de todas as materializações simbólicas impostas a ele por uma elite conservadora, opressora e produtora de desigualdades, desse modo, esses temas em sala de aula permitem uma apropriação do corpo como patrimônio fundamental, como ferramenta de libertação e vivência de uma nova experiência espacial. Conhecer e se libertar das amarras imposta a corporeidade é um passo importante para conhecer a si mesmo e o mundo (Quadro 2).

Quadro 2. Algumas referências importantes a respeito de gênero e sexualidade.

\begin{tabular}{|c|c|c|c|}
\hline Autor (Citação) & Título da obra & Revista/Editora & $\begin{array}{c}\text { Ano de } \\
\text { publicação }\end{array}$ \\
\hline $\begin{array}{c}\text { CARVALHAES, } \\
\text { Flavia Fernandes e et } \\
\text { al }\end{array}$ & $\begin{array}{c}\text { Territórios, Gerações \& Cultura: } \\
\text { (Des)continuidades das Expressões de } \\
\text { Gênero entre Lésbicas. }\end{array}$ & $\begin{array}{c}\text { Revista Latino- } \\
\text { americana de } \\
\text { Geografia e } \\
\text { Gênero }\end{array}$ & 2011 \\
\hline $\begin{array}{c}\text { CASTRO, Jânio } \\
\text { Roque Barros de }\end{array}$ & $\begin{array}{c}\text { Paisagens e visões míticas, questões de } \\
\text { gênero e a cidade no romance "Mar } \\
\text { Morto", de Jorge Amado }\end{array}$ & Geograficidade & 2015 \\
\hline $\begin{array}{c}\text { ZDEBSKYI, Janaína } \\
\text { de Fátima; }\end{array}$ & $\begin{array}{c}\text { A histérica e as belas, recatadas e do lar: } \\
\text { MARANHÃO, } \\
\text { misoginia à Dilma Rousseff na concepção } \\
\text { das mulheres como costelas e dos homens } \\
\text { de Albuquerque; } \\
\text { PEDRO, Joana } \\
\text { Maria }\end{array}$ & $\begin{array}{c}\text { Espaço e cultura } \\
\text { começa da política brasileira }\end{array}$ & 2015 \\
\hline
\end{tabular}




\section{REVISTA ELETRÔNICA \\ DA GRADUAÇÃO/PÓS-GRADUAÇÃO EM EDUCAÇÃO \\ UFG/REJ}

ISSN. 1807-9342

Volume 14, N. 2, 2018

\begin{tabular}{|c|c|c|c|}
\hline $\begin{array}{l}\text { ABRANCHES } \\
\text { JUNIOR, Nilton; } \\
\text { ALMEIDA NETO, } \\
\text { Arthur Marques de }\end{array}$ & $\begin{array}{l}\text { Religião, gênero e território: discursos } \\
\text { midiáticos da parada gay de São Paulo }\end{array}$ & Espaço e cultura & 2015 \\
\hline $\begin{array}{l}\text { COSTA, Carmen } \\
\text { Lúcia }\end{array}$ & $\begin{array}{c}\text { A Presença e Ausência do Debate de } \\
\text { Gênero na Geografia do Ensino } \\
\text { Fundamental e Médio }\end{array}$ & $\begin{array}{l}\text { Revista Latino- } \\
\text { americana de } \\
\text { Geografia e } \\
\text { Gênero }\end{array}$ & 2011 \\
\hline
\end{tabular}

Elaboração: Rodrigo Capelle Suess, 2018.

- Uma abordagem científica da religião permite desvelar o seu impacto na construção dos lugares e dos significados, as emoções que evoca o deslocamento das pessoas, a territorialidade e identidade que a fé compõe, por outro lado, igualmente, debater a opressão que muitas religiões impõem a determinados sujeitos e grupos. O mais importante desse debate em sala de aula é propiciar um sentimento de tolerância a manifestação religiosa que não seja a minha, trata-se de desenvolver o respeito mútuo, a desconstrução da indiferença e da resistência daquilo que difere da minha fé (Quadro 3).

Quadro 3. Algumas referências importantes a respeito da religião e Geografia.

\begin{tabular}{|c|c|c|c|}
\hline Autor (Citação) & Título da obra & Revista/Editora & Ano \\
\hline $\begin{array}{c}\text { ROSENDAHL, } \\
\text { Zeny }\end{array}$ & $\begin{array}{c}\text { Os caminhos da construção teórica: } \\
\text { ratificando as relações entre espaço e } \\
\text { religião }\end{array}$ & Ed. UERJ & 2013 \\
\hline $\begin{array}{c}\text { ROSENDAHL, } \\
\text { Zeny }\end{array}$ & Hierópolis: O Sagrado e o urbano & Ed. UERJ & 2013 \\
\hline $\begin{array}{c}\text { CORREิA, } \\
\text { Mureanice de }\end{array}$ & $\begin{array}{c}\text { "Não acredito em deuses que não saibam } \\
\text { dançar": a festa do candomblé, território } \\
\text { encarnador da cultura }\end{array}$ & Ed. UERJ & 2013 \\
\hline $\begin{array}{c}\text { SOUZA, Cleiton } \\
\text { Roberto Perpeto }\end{array}$ & $\begin{array}{c}\text { Religião e política: o mundo evangélico e a } \\
\text { geografia do voto }\end{array}$ & Espaço e cultura & 2015 \\
\hline $\begin{array}{c}\text { GIL FILHO, } \\
\text { Sylvio Fausto }\end{array}$ & $\begin{array}{c}\text { Espacialidades de conformação simbólica } \\
\text { em geografia da religião: um ensaio } \\
\text { epistemológico }\end{array}$ & Espaço e cultura & 2012 \\
\hline
\end{tabular}

Elaboração: Rodrigo Capelle Suess, 2018.

- Literatura e poesia se constituem em uma das mais ricas abordagens que o ensino de Geografia pode lançar por meio da contribuição do horizonte humanista em Geografia. Como ressaltam Marandola Jr. e Gratão (2012, p. 14), a ciência demorou muito para levar em conta a literatura, por muito tempo a capacidade da literatura em despertar descobertas, sonhos, desejos e sentidos, ou melhor, "o jeito caloroso do Ser Humano" foi ignorado. Agora, temos a possibilidade de forma interdisciplinar com a Artes e Língua 


\section{REVISTA ELETRÔNICA \\ DA GRADUAÇÃO/PÓS-GRADUAÇÃO EM EDUCAÇÃO \\ UFG/REJ}

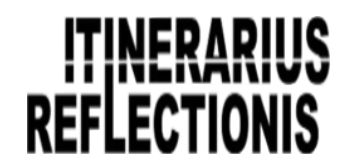

ISSN. 1807-9342

Volume 14, N. 2, 2018

Portuguesa, ou de modo disciplinar, utilizar a literatura e a poesia para explorar um conhecimento espacial que nenhum outro cientista é capaz de produzir (Quadro 4).

\section{Quadro 4. Algumas referências importantes a respeito da literatura, poesia e} Geografia.

\begin{tabular}{|c|c|c|c|}
\hline Autor (Citação) & Título da obra & Revista/Editora & Ano \\
\hline $\begin{array}{l}\text { MARANDOLA } \\
\text { JR., Eduardo; } \\
\text { GRATÃO, Lúcia } \\
\text { Helena Batista } \\
\quad \text { (orgs.) }\end{array}$ & $\begin{array}{l}\text { Geografia e Literatura: ensaios sobre } \\
\text { geograficidade, poética e imaginação }\end{array}$ & Eduel & 2010 \\
\hline $\begin{array}{l}\text { BROSSEAU, } \\
\text { Marc }\end{array}$ & Geografia e Literatura & Ed. UERJ & 2013 \\
\hline $\begin{array}{l}\text { HAESBAERT, } \\
\text { Rogério } \\
\end{array}$ & Território, poesia e identidade & Espaço e Cultura & 1997 \\
\hline $\begin{array}{l}\text { SILVA, Felipe } \\
\text { Cabanas da }\end{array}$ & $\begin{array}{l}\text { Por uma geografia da lírica: representações } \\
\text { do espaço na poesia de Carlos Drummond } \\
\text { de Andrade (Sentimento do mundo, A rosa } \\
\text { do povo e Menino antigo) }\end{array}$ & $\begin{array}{l}\text { Universidade de } \\
\text { São Paulo }\end{array}$ & 2015 \\
\hline $\begin{array}{l}\text { FERREIRA, } \\
\text { Rosângela Veiga } \\
\text { Julio; FARIA, } \\
\text { Jeniffer de Souza }\end{array}$ & $\begin{array}{c}\text { A literatura como potência } \\
\text { problematizadora do lugar: imagens } \\
\text { projetadas pelas crianças. Geograficidade }\end{array}$ & Geograficidade & 2012 \\
\hline
\end{tabular}

Elaboração: Rodrigo Capelle Suess, 2018.

- Como os avanços relacionados a revolução técnico-científica informacional vivenciados a partir da década de 1970, houve mudanças significativas em diversos setores, entre eles o cinema. Com isso, embora a produção global seja concentrada, principalmente, na indústria cinematográfica americana, há uma diversidade de produções independentes e de menor escala que, associadas ou não a grandes produções, podem ser exploradas em sala de aula na abordagem de múltiplos conteúdos geográficos. Trata-se de uma rica ferramenta audiovisual de ensino, uma nova textualidade do espaço geográfico, que intermedia por meio do "mundo real" e do "mundo ficcional" a (re)construção e a organização do espaço geográfico, sobretudo, a representação da dimensão imaginária e simbólica (COSTA, 2012) (Quadro 5).

Quadro 5. Algumas referências importantes a respeito do cinema e Geografia.

\begin{tabular}{|c|c|c|c|}
\hline Autor (Citação) & Título da obra & Revista/Editora & $\begin{array}{c}\text { Ano de } \\
\text { publicação }\end{array}$ \\
\hline $\begin{array}{c}\text { COSTA, Maria } \\
\text { Helena Braga }\end{array}$ & $\begin{array}{c}\text { Geografia cultural e cinema: práticas, teorias } \\
\text { e métodos }\end{array}$ & Ed. UERJ & 2013 \\
\hline
\end{tabular}




\section{REVISTA ELETRÔNICA \\ DA GRADUAÇÃO/PÓS-GRADUAÇÃO EM EDUCAÇÃO \\ UFG/REJ}

ISSN. 1807-9342

Volume 14, N. 2, 2018

\begin{tabular}{|c|c|c|c|}
\hline $\begin{array}{c}\text { CORRÊA, Roberto } \\
\text { Lobato; } \\
\text { ROSENDAHL, } \\
\text { Zeny. }\end{array}$ & Cinema, música e espaço & Ed. UERJ & 2009 \\
\hline $\begin{array}{c}\text { COSTA, Maria } \\
\text { Helena Braga e Vaz } \\
\text { da }\end{array}$ & $\begin{array}{c}\text { Cidades e lugares culturais, espaços e } \\
\text { geografias fílmicas: compondo } \\
\text { imageticamente o lugar }\end{array}$ & Espaço e cultura & 2014 \\
\hline $\begin{array}{c}\text { BOER, Gabriela } \\
\text { Laurito }\end{array}$ & $\begin{array}{c}\text { Geografia e cinema: outras imagens para se } \\
\text { pensar a fronteira' }\end{array}$ & $\begin{array}{c}\text { Universidade } \\
\text { Federal de } \\
\text { Grande Dourados }\end{array}$ & 2015 \\
\hline $\begin{array}{c}\text { MOREIRA, Tiago } \\
\text { de Almeida }\end{array}$ & $\begin{array}{c}\text { Ensino de geografia com o uso de filmes no } \\
\text { Brasil }\end{array}$ & Revista Geousp & 2012 \\
\hline
\end{tabular}

Elaboração: Rodrigo Capelle Suess, 2018.

- As imagens se constituem em ótimas ferramentas para se ler o mundo, tentar compreendê-lo ou até mesmo para efeito contemplativo de sua complexidade. Para Gomes e Ribeiro (2013) a construção do pensamento geográfico tem como grande contribuidor a participação direta das imagens, significando, principalmente, instrumentos de descoberta, pois, por meio delas podemos perceber comportamentos, gestos, maneiras de se apresentar, de falar, de estar, de produzir significações associadas a localização precisa do evento. Para isso, o uso de imagens no ensino de Geografia não deve ser apenas ilustrativo, mas compositivo de um enredo, de uma história, de uma memória de importância local, regional, nacional e até mesmo global. Além do professor resgatar as imagens, deve pedir para que os alunos produzam ou divulguem imagens de seu acervo particular ou familiar que reflitam o tema analisado em sala de aula (Quadro 6)

Quadro 6. Algumas referências relevantes a respeito da imagem e Geografia.

\begin{tabular}{|c|c|c|c|}
\hline Autor (Citação) & Título da obra & Revista/Editora & $\begin{array}{c}\text { Ano de } \\
\text { publicação }\end{array}$ \\
\hline MARQUES, Ivania & $\begin{array}{c}\text { Imagear: o lugar, os viajantes e as } \\
\text { imagens }\end{array}$ & Geograficidade & 2012 \\
\hline $\begin{array}{l}\text { FERRAZ, Cláudio } \\
\text { Benito Oliveira }\end{array}$ & $\begin{array}{c}\text { Geografia e Paisagem: entre o olhar e o } \\
\text { pensar' }\end{array}$ & $\begin{array}{l}\text { Universidade de São } \\
\text { Paulo }\end{array}$ & 2002 \\
\hline $\begin{array}{l}\text { LENZI, Maria } \\
\text { Helena }\end{array}$ & $\begin{array}{c}\text { Das imagens, a ausência: aportes teóricos } \\
\text { para o estudo das imagens da cidade na } \\
\text { geografia }\end{array}$ & Geograficidade & 2012 \\
\hline $\begin{array}{c}\text { NOVAES, André } \\
\text { Reyes }\end{array}$ & $\begin{array}{l}\text { Um Mapa do Tráfico no Livro Didático: } \\
\text { Encontros e Desencontros entre Geografia } \\
\text { Escolar e Cartografia Midiática }\end{array}$ & Geograficidade & 2012 \\
\hline $\begin{array}{c}\text { NOVAES, André } \\
\text { Reyes }\end{array}$ & $\begin{array}{c}\text { Uma geografia visual? Contribuições para } \\
\text { o uso das imagens na difusão do } \\
\text { conhecimento geográfico }\end{array}$ & Espaço e cultura & 2011 \\
\hline
\end{tabular}

Elaboração: Rodrigo Capelle Suess, 2018. 


\section{REVISTA ELETRÔNICA \\ DA GRADUAÇÃO/PÓS-GRADUAÇÃO EM EDUCAÇÃO UFG/REJ}

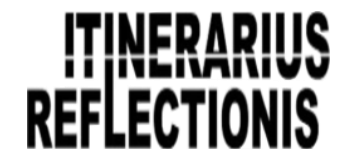

ISSN. 1807-9342

Volume 14, N. 2, 2018

- A música pode ser utilizada em Geografia como conteúdo e procedimento metodológico tendo em vista a construção de conhecimentos geográficos. Ela também se constitui como uma textualidade possível do espaço, uma vez que, elas podem expressar corporeidades, experiências, sentimentos, gostos e desgostos, críticas e posicionamentos dos cantores/compositores que emanam nos indivíduos ou coletivos identidades compartilhadas ou não. As músicas podem resguardar um rico conteúdo em múltiplas dimensões - simbólicas, sociais, econômicas e naturais. Desse modo, essa arte pode revelar fatores geográficos não encontrados na academia, nos livros ou nos meios de comunicação que são valorativos para uma perspectiva de construção de conhecimentos voltada à cidadania (Quadro 7).

Quadro 7. Algumas referências relevantes a respeito da música e Geografia.

\begin{tabular}{|c|c|c|c|}
\hline Autor (Citação) & Título da obra & Revista/Editora & $\begin{array}{c}\text { Ano de } \\
\text { publicação }\end{array}$ \\
\hline $\begin{array}{c}\text { MELLO, João } \\
\text { Baptista Ferreira de }\end{array}$ & $\begin{array}{c}\text { O Rio de Janeiro dos compositores da música } \\
\text { popular brasileira 1928/1991 - uma } \\
\text { introdução a Geografia humanística }\end{array}$ & $\begin{array}{c}\text { Universidade } \\
\text { Federal do Rio } \\
\text { de Janeiro }\end{array}$ & 1991 \\
\hline $\begin{array}{c}\text { MELLO, João } \\
\text { Baptista Ferreira de } \\
\text { extrema luminosidade - o universo da estrela } \\
\text { Marlene como palco e documento para a } \\
\text { construção de conceitos geográficos }\end{array}$ & $\begin{array}{c}\text { Universidade } \\
\text { Federal do Rio } \\
\text { de Janeiro }\end{array}$ & 2000 \\
\hline $\begin{array}{c}\text { PANITZ, Lucas } \\
\text { Manassi }\end{array}$ & $\begin{array}{c}\text { Por uma geografia da música: o espaço } \\
\text { geográfico da música popular platina }\end{array}$ & $\begin{array}{c}\text { Universidade } \\
\text { de São Paulo }\end{array}$ & 2010 \\
\hline $\begin{array}{c}\text { PANITZ, Lucas } \\
\text { Manassi }\end{array}$ & $\begin{array}{c}\text { Geografia e música: uma introdução ao tema } \\
\text { Biblio W3 }\end{array}$ & 2011 \\
\hline $\begin{array}{c}\text { OLIVEIRA, Hélio } \\
\text { earlos Miranda de }\end{array}$ & $\begin{array}{c}\text { A música como recurso alternativo nas } \\
\text { práticas educativas em Geografia: algumas } \\
\text { reflexões }\end{array}$ & $\begin{array}{c}\text { Caminhos de } \\
\text { Geografia }\end{array}$ & 2015 \\
\hline $\begin{array}{c}\text { FUINI, Lucas } \\
\text { Labigalini e et al }\end{array}$ & $\begin{array}{c}\text { A música como instrumento para o ensino de } \\
\text { geografia e seus conceitos fundamentais: } \\
\text { pensando em propostas para o trabalho em } \\
\text { sala de aula }\end{array}$ & $\begin{array}{c}\text { Para Onde!? } \\
\text { Revista de pós- } \\
\text { graduação em } \\
\text { Geografia da } \\
\text { UFRGS }\end{array}$ & 2012 \\
\hline
\end{tabular}

Elaboração: Rodrigo Capelle Suess, 2018.

- Símbolos e significados permitem o professor ir além das tradicionais dimensões políticas, sociais e econômicas, permitem abordar, igualmente, o fenômeno em sua dimensão cultural, especialmente, simbólica. Conforme White e Dillingham (2009), um símbolo é composto de dois elementos, o significado e a estrutura física (objeto, um ato, uma cor ou um som...). Esse último é responsável por se constituir em um veículo transmissor de significado. Segundo Corrêa (2012, p. 134) os significados "são construções intelectuais que visam dar sentido às esferas da vida". Esse intelectual tendo 


\section{REVISTA ELETRÔNICA \\ DA GRADUAÇÃO/PÓS-GRADUAÇÃO EM EDUCAÇÃO \\ UFG/REJ}

\section{ITINEPARPIUS REFLECTIONIS}

ISSN. 1807-9342

Volume 14, N. 2, 2018

como base Cassirer (2001), confere que compreender os significados criados por nós e pelos outros se constitui em uma forma de construir um conhecimento mais profundo de um dado aspecto da realidade, além do conhecimento de sua organização, constituição e estrutura. Desse modo, trata-se de uma possibilidade de estudar a dimensão simbólica do espaço geográfico no processo educativo em Geografia, mediado, principalmente, pelo conceito de lugar e paisagem.

Quadro 8. Algumas referências a respeito dos símbolos, significados e Geografia.

\begin{tabular}{|c|c|c|c|}
\hline $\begin{array}{c}\text { Autor (Citação) } \\
\text { OLIVEIRA, Lívia } \\
\text { de }\end{array}$ & Título da obra & Revista/Editora & $\begin{array}{c}\text { Ano de } \\
\text { publicação }\end{array}$ \\
\hline $\begin{array}{c}\text { CORRÊA, Roberto } \\
\text { Lobato }\end{array}$ & Espaço e simbolismo & Bertrand Brasil & 2015 \\
\hline COSTA, Otávio & $\begin{array}{c}\text { Memória e paisagem: em busca do } \\
\text { simbólico dos lugares }\end{array}$ & Espaço e cultura & 2003 \\
\hline $\begin{array}{c}\text { MELLO, João } \\
\text { Baptista Ferreira de }\end{array}$ & $\begin{array}{c}\text { O Rio dos Símbolos Oficiais e } \\
\text { Vernaculares }\end{array}$ & Ed. UERJ & $2008^{\mathrm{a}}$ \\
\hline $\begin{array}{c}\text { MELLO, João } \\
\text { Baptista Ferreira de }\end{array}$ & $\begin{array}{c}\text { Símbolos dos lugares, dos espaços e dos } \\
\text { "deslugares" }\end{array}$ & Espaço e cultura & $2008 \mathrm{~b}$ \\
\hline
\end{tabular}

Elaboração: Rodrigo Capelle Suess, 2018.

- Mundo vivido ou espaço vivido é um importante conceito da fenomenologia incorporado e adaptado a uma perspectiva do espaço geográfico. Mundo vivido sugere um mundo prático de dimensões pré-reflexivas, entrelaçado pela experiência vivida (BUTTIMER, 1982). Um mundo que se forma para o indivíduo a partir da junção do mundo concreto e imaterial, nele é possível uma construção objetiva, subjetiva e intersubjetiva. Cabe o professor de Geografia utilizar essa importante noção, especialmente, mediado pelo conceito de lugar, para se constituir em ponto de partida em vista a construção de conhecimentos geográficos. Trata-se de utilizar as experiências dos alunos com o espaço que é vivido para mediar a construção de conceitos científicos, em uma relação concreta-abstrata, sincrética-sintética, inspirado no processo de construção de conhecimentos científicos de Vigotsky (2008) (QUADRO, 9).

Quadro 9. Referências a respeito do mundo vivido e Geografia.

\begin{tabular}{|c|c|c|c|}
\hline Autor (Citação) & Título da obra & Revista/Editora & $\begin{array}{c}\text { Ano de } \\
\text { publicação }\end{array}$ \\
\hline BUTTIMER. Anne & Aprendendo o dinamismo do mundo vivido. & Difel & 1982 \\
\hline $\begin{array}{c}\text { BOLLNOW, Otto } \\
\text { Friedrich }\end{array}$ & O homem e o Espaço & Ed. UFPR & 2008 \\
\hline
\end{tabular}




\section{REVISTA ELETRÔNICA \\ DA GRADUAÇÃO/PÓS-GRADUAÇÃO EM EDUCAÇÃO UFG/REJ}

\begin{tabular}{|c|c|c|c|}
\hline $\begin{array}{c}\text { FREMÓNT, } \\
\text { Armand. }\end{array}$ & A região, espaço vivido & Almedina & 1980 \\
\hline YI-FU, Tuan & $\begin{array}{c}\text { Espaço e Lugar: a perspectiva da } \\
\text { experiência. }\end{array}$ & Eduel & 2013 \\
\hline $\begin{array}{c}\text { CARVALHO } \\
\text { SOBRINHO, Hugo } \\
\text { de }\end{array}$ & $\begin{array}{c}\text { Geografia escolar e o lugar: a construção de } \\
\text { conhecimentos no processo de } \\
\text { ensinar/aprender geografia }\end{array}$ & Geosaberes & 2018 \\
\hline $\begin{array}{c}\text { LEITE, Cristina } \\
\text { Maria Costa. }\end{array}$ & $\begin{array}{c}\text { O lugar e a construção da identidade: os } \\
\text { significados construídos por professores de } \\
\text { Geografia do ensino fundamental }\end{array}$ & $\begin{array}{c}\text { Universidade de } \\
\text { Brasília }\end{array}$ & 2012 \\
\hline
\end{tabular}

Elaboração: Rodrigo Capelle Suess, 2018.

As metodologias, temáticas e teorias apresentadas não esgotam a diversidade e as múltiplas abordagens de um mesmo fenômeno propostas pelo horizonte humanista em Geografia. Outros temas, como biografia, identidade, formas simbólicas, espaço público, economia (cultural), imaginário espacial, identidade territorial, ambientes alternativos, utopias e sonhos também podem e devem ser ressiginificados no âmbito da trabalho pedagógico do professor e do aluno com intuito cada vez maior de contribuir para a formação de cidadãos que entendam e se apropriem de seu corpo, gostos e desgostos, compreendem o outro, e a partir daí se apropriam e transformam, individualmente e coletivamente, o espaço geográfico. Do mesmo modo, a ressiginificação do espaço geográfico e de seus conceitos como lugar, paisagem, região e território impõe uma nova agenda de debates para a Geografia, e consequentemente, para um ensino de geografia pautado no horizonte humanista.

\section{NOVOS CAMINHOS PARA O ENSINO: algumas experiências acadêmicas e pedagógicas}

Vislumbramos nesse momento, nessa berlinda de caminhos metodológicos, teóricos e temáticos, apresentar algumas aplicações práticas por parte do autor desse artigo e suas implicações para o ensino.

No trabalho de Carvalho Sobrinho, Suess e Bezerra (2014), intitulado "Geografia, cidade e lugar no processo de ensino-aprendizagem: um enfoque a partir da cidade de Formosa-GO", exploramos a possibilidade da cidade enquanto dimensão vivida e simbólica se constituir como uma proposta pedagógica, mediada, em Geografia, pelo conceito de lugar, para a construção de conhecimentos geográficos significativos. Defendemos explorar os espaços que rodeiam a escola e que são percebidos pelos alunos 


\title{
REVISTA ELETRÔNICA \\ DA GRADUAÇÃO/PÓS-GRADUAÇÃO EM EDUCAÇÃO \\ UFG/REJ
}

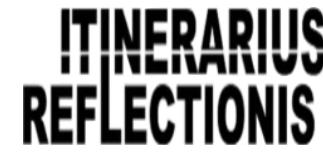

ISSN. 1807-9342

Volume 14, N. 2, 2018

do caminho de casa para escola no intuito de levá-los a conhecer, intervir e (re) criar a sua cidade. Dessa maneira:

\begin{abstract}
A cidade de Formosa-GO, com mais de 100.000 habitantes e 170 anos de história, com seus festejos, manifestações culturais e religiosas, com seus recursos naturais exuberantes, mas também, com problemas e situações peculiares de uma cidade que se desenvolve, detém locais que podem ser assumidos como uma sala de aula (CARVALHO SOBRINHO, SUESS e BEZERRA, 2014).
\end{abstract}

$\mathrm{Na}$ investigação intitulada "versos, estrofes e rimas: o lugar do estado de Goiás nos poemas e poesias" (CARVALHO SOBRINHO e SUESS, 2018) exploramos essas formas de criação e expressão humana, mediadas pelo arcabouço teórico da Geografia, sobretudo, àquele de inspiração humanista, como um modo de ler e interpretar o mundo, no caso específico, o Estado de Goiás. Assim, um dos principais objetivos desse trabalho foi evidenciar, por meio de poemas e poesias que retratam o Estado de Goiás, a alma desses lugares.

Em linha semelhante, Suess e Bezerra (2005) no artigo "o espaço do cerrado contado por meio de versos, estrofes e rimas: uma leitura realizada por meio da perspectiva do lugar" objetivamos analisar o Cerrado, bioma que abrange cerca de 2 milhões de $\mathrm{km}^{2}$, equivalente a quase um quarto do território nacional sendo, portanto, o segundo maior bioma brasileiro e também a savana tropical mais rica e ameaçada do planeta, por meio da sua representação em poemas e poesias, utilizando com ferramenta o conceito de lugar. Nota-se que muitos poemas e poesias expõem os valores construídos entre indivíduos e meio ambiente e são importantes auxiliares para o desenvolvimento do ensino-aprendizagem que permita ao aluno desenvolver novas formas de raciocínio e de valorização de sua própria cultura. Assim, constitui-se numa concepção de ensinoaprendizagem que, de forma interdisciplinar, faz com que o aluno possua uma visão holística do seu lugar, isto é, uma visão que não reduza esse ao local, dando subsídios, assim, para a compreensão dos lugares globais.

Desse modo, nota-se que por meio dos poemas e poesias, emanam elementos e valores importantes no processo de ensino-aprendizagem, em geral, e também, em um processo específico de construção de conhecimentos geográficos, falamos das referências pessoais de cada um, do lugar, da afetividade, dos costumes de um povo, da valorização 


\section{REVISTA ELETRÔNICA \\ DA GRADUAÇÃO/PÓS-GRADUAÇÃO EM EDUCAÇÃO \\ UFG/REJ}

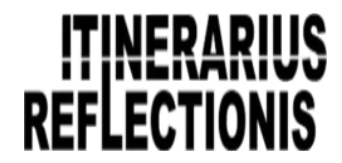

ISSN. 1807-9342

Volume 14, N. 2, 2018

da cultura regional, das experiências, percepções e memórias. Traços que outros textos e formas de expressões de cunho mais científico pouco ou quase nada poderiam fornecer.

Outra linha que vem sendo desenvolvida com ênfase pelo autor é a relação da música com a Geografia. Pois, acreditamos que a música, assim como os poemas e poesias, além de propagadora de cultura, destaca-se por ser uma forte condutora de identidade e reveladora da alma dos lugares, constituindo-se, em uma importante ferramenta para o ensino de Geografia. Essa perspectiva pode ser vista nos seguintes trabalhos: "uma leitura do estado de Goiás (Brasil): elos entre música, território e lugar", “o 'lugar’ de Goiás nas letras de músicas sertanejas: uma abordagem geográfica”, "música e ensino de geografia: o estudo da geografia de Goiás por meio de músicas com alunos do ensino médio em Formosa-Goiás" e "Música e ensino de geografia: o estudo da Geografia de Goiás por meio de músicas com alunos do Ensino Médio em Formosa-GO” (SUESS e ALMEIDA, 2015; SUESS, 2016; CARVALHO SOBRINHO, SUESS e DOURADO, 2016).

Questões mais teóricas e biografias também são ótimas referências para o processo de ensino-aprendizagem. Assim, a teoria freiriana e o conceito de lugar são temáticas que podem contribuir para a educação geográfica. Os valores defendidos por Paulo Freire na educação podem ser facilmente apropriados pelo processo educativo em Geografia, em especial, o guiado pela Geografia humanista. Desse modo, humildade, sabedoria, respeito à diversidade, esperança, alegria, tolerância, curiosidade, diálogo, consideração aos sentimentos, emoções e sonhos, constituem-se atributos, que podem ser apropriados pelo processo de ensino-aprendizagem em Geografia, na orientação pela Geografia humanista. Contudo, não são apenas os valores defendidos por Freire que são significativos para esse processo. Sua defesa em se utilizar do senso comum como ponto de partida para construção de conhecimentos, a necessidade de reconhecer o contexto onde o aluno se insere, antes de sua teorização, o aproxima de um processo empreendido pelo humanismo/fenomenologia (SUESS e LEITE, 2017).

No artigo "Lugar e Geografia Humanista: possibilidade de ensinar-aprender geografia" o autor defende que o conceito lugar em uma perspectiva da Geografia humanista contribui para um processo de ensino-aprendizagem que conduz o aluno a compreender melhor a si mesmo e o mundo em que vive, sem menosprezar os aspectos cognitivos, afetivos, físicos, éticos e estéticos, que possam interferir no exercício da 


\section{REVISTA ELETRÔNICA \\ DA GRADUAÇÃO/PÓS-GRADUAÇÃO EM EDUCAÇÃO \\ UFG/REJ}

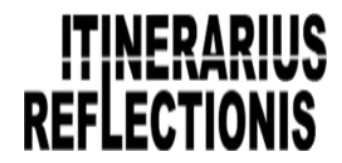

ISSN. 1807-9342

Volume 14, N. 2, 2018

cidadania e, ainda, de uma atuação e inserção social mais consciente e humanista. Sendo assim, acreditamos que o lugar contribui para que os discentes se reconheçam como sujeitos, com possibilidade concreta de atuação no espaço por meio do seu lugar, compreendam as aparências, ausências e múltiplas manifestações dos fenômenos geográficos, ressignificados à luz de suas próprias experiências (SUESS, 2016a).

Por meio de aplicação desse conceito em sala de aula com alunos do $6^{\circ}$ ano do ensino fundamental em uma escola do Distrito Federal, o lugar possibilitou descobrir diversas vulnerabilidades socioeconômicas que muitos alunos sofrem em seus contextos e permitiu que os alunos vejam a Geografia mais próxima de suas realidades e não apenas restrita ao livro didático e a sala de aula. Além disso, foi possível observar e reforçar o fato que as vivências e o convívio familiar influenciam nas percepções sobre os lugares e sobre as coisas, gerando diversas concepções de mundo que podem ser trabalhadas no âmbito do espaço escolar (SUESS, 2016b).

Nota-se que parte majoritária de experiências e teorizações em Geografia escolar e em Geografia humanista é voltada para o espaço urbano. Contudo, há uma parcela significativa da população brasileira mora ou tem a sua identidade voltada ao campo. Por isso, acreditamos que as teorizações que façam relação com a valorização da educação no campo em uma perspectiva humanista são de extrema importância. A respeito disso foram desenvolvidos dois trabalhos: "educação no/do Campo: Desafios e perspectivas de uma escola no campo localizada no Distrito Federal" e "lugar de vida e luta no meio rural de Formosa (Goiás - Brasil): Pré-assentamento Fartura/Miguel Caetano" (CARVALHO SOBRINHO, SUESS e LEITE, 2016). Os cenários apresentados não são dos mais favoráveis, por diversos problemas socioeconômicos que se agravam e persistem, em partes, pela negligência do poder público. Contudo, é na educação o principal projeto de mudança. Por meio da educação acreditamos que é possível levar esses sujeitos a construírem conhecimentos úteis para a transformação e ressignificação do espaço geográfico do campo por meio da luta e a valorização do lugar em todas as suas dimensões.

A percepção é uma das dimensões mais utilizadas na construção de conhecimentos, embora com pouca vinculação a um projeto de Geografia e de Educação. Trabalhar com percepção, segundo Tuan (1980), é trabalhar com os sentidos, com a dimensão da paisagem. Nesse sentido, o trabalho intitulado "Percepção ambiental de 


\section{REVISTA ELETRÔNICA \\ DA GRADUAÇÃO/PÓS-GRADUAÇÃO EM EDUCAÇÃO UFG/REJ}

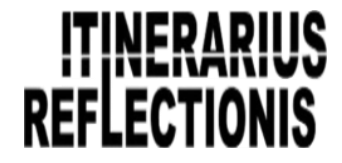

ISSN. 1807-9342

Volume 14, N. 2, 2018

diferentes atores sociais sobre o lago do Abreu em Formosa - GO" permitiu o entendimento de como se dá a relação desses sujeitos com o ambiente, assim como fornece subsídios para uma política de preservação desse meio e o planejamento de projetos em educação ambiental que possam envolver ativamente a comunidade local. Pois, levantou-se que o ambiente do Lago do Abreu tem grande potencial para o desenvolvimento de atividades educacionais das escolas do município, porém os entrevistados relatam que tal potencial não vem sendo aproveitado mostrando a necessidade de realizar projetos em escolas voltados à Educação Ambiental e conscientização da população local para a preservação do ambiente (SUESS, BEZERRA e CARVALHO SOBRINHO, 2014).

A saída de campo é muito significativa para a educação. Em Geografia ela permite o contato direto do aluno com o espaço geográfico estudado, trata-se da experiência geográfica tão defendida pela Geografia humanista. No artigo intitulado "concepções de moradores e turistas no distrito de São Jorge-GO: uma reconstrução cultural" a saída de campo permitiu analisar a influência da natureza sobre aspectos culturais locais, a interação de culturas diferentes no mesmo espaço e a relação dos habitantes e dos turistas com a natureza no distrito de São Jorge, localizado no município de Alto Paraíso - GO e concluir que a cultura se destaca, atualmente, em São Jorge por estar em transformação, onde o tradicional e o mítico, o novo e o velho, o sagrado e o profano, se misturam dando uma nova roupagem para o distrito (SUESS e BEZERRA, 2013).

Dessa forma, acreditamos que essas experiências com pesquisas epistemológicas, empíricas e escolares reforçam as ideias defendidas nesse trabalho, uma vez que, as proposições e reflexões realizadas aqui, também são fruto de uma trajetória enquanto professor e pesquisador em Geografia, com grande dedicação as temáticas do horizonte humanista em Geografia e a preocupação com a Geografia escolar.

\section{ALGUMAS CONSIDERAÇÕES}

O horizonte humanista se consolidou ao longo das últimas décadas e vem paulatina e progressivamente se constituindo numa importante via de análise e de compreensão em Geografia. Seu nascimento decorre de um contexto de insatisfação às ferramentas analíticas que não davam conta de explicar diversos problemas em um mundo 


\section{REVISTA ELETRÔNICA \\ DA GRADUAÇÃO/PÓS-GRADUAÇÃO EM EDUCAÇÃO UFG/REJ}

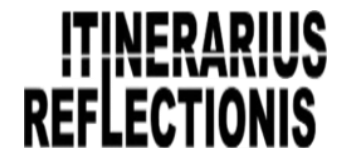

ISSN. 1807-9342

Volume 14, N. 2, 2018

cada vez mais definido e acelerado pela ciência, novos meios de comunicações e transportes, ao passo que o homem ficava cada vez mais distante das explicações científicas, forjado por uma falsa sensação de neutralidade, além do desdém a metafísica, artes, literatura e mundo da vida.

Com isso diversas dimensões ficaram subjugadas e pouco representadas na ciência geográfica, especialmente, na esfera subjetiva e cultural. Tais temas e metodologias eram vistas com um saber inferior, sem cientificidade e de pouca utilidade. Contudo, a Geografia humanista, movimento de renovação que surgiu na Geografia a partir da década de 1960, e a Nova Geografia cultural, ruptura dentro de um campo do saber já consolidado em Geografia - a Geografia cultural, ambas constitui um novo horizonte/abordagem em Geografia, fundamental para ressignificar a Geografia e resgatar esses temas e metodologias marginalizadas até então.

Nesse aspecto, as artes, a música, as imagens, o cinema, a literatura, os poemas e poesias, o lugar e o mundo vivido, os símbolos e significados, a discussão de gênero e sexualidade e entre outras abordagens, além da aproximação da dimensão cultural com outras dimensões, especialmente, com a esfera econômica e política, foram transformadas em novas temáticas e metodologias da Geografia, desenvolvidas por um horizonte humanista. Assim, já são discussões bem consolidadas no âmbito teórico, contudo, sua relação com o ensino ainda é pouco explorada pelos geógrafos humanistas/culturais.

Desse modo, esse ensaio vislumbrou fazer algumas interconexões entre possibilidades temáticas e metodológicas da Geografia humanista e Geografia escolar. Para isso, desenvolvemos algumas análises teóricas e reflexões a partir de experiências pedagógicas em sala de aula que permitiram propor novos caminhos para o ensino de Geografia. Consideramos que o campo é extremamente fértil para a Geografia escolar, contudo ainda pouco explorado. Acreditamos que algumas das reflexões realizadas nesse trabalho podem incentivar e subsidiar novos desenvolvimentos na área, além de se constituir como uma referência teórica.

\section{REFERÊNCIAS}

ABRANCHES JUNIOR, N.; ALMEIDA NETO, A. M. Religião, gênero e território: discursos midiáticos da parada gay de São Paulo. Espaço e cultura, RJ, n. 38, p. 205224, jul./dez. 2015. 


\section{REVISTA ELETRÔNICA \\ DA GRADUAÇÃO/PÓS-GRADUAÇÃO EM EDUCAÇÃO UFG/REJ}

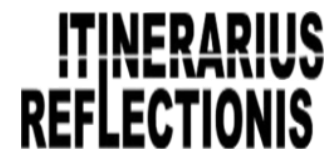

ISSN. 1807-9342

Volume 14, N. 2, 2018

BAILLY, A.; SCARIATI, R. L'humanisme en géographie. In: BAILLY, Antoine. Les concepts de la géographie humanine. Paris: Armand Colin, p.213-222, 2001.

BARROS, J. D. História, espaço, geografia: diálogos interdisciplinares. São Paulo: Editora Vozes, 2017.

BOER, G. L. Geografia e cinema: outras imagens para se pensar a fronteira. 2015. Dissertação (mestrado em Geografia) Programa de Pós-graduação em Geografia, Universidade Federal de Grande Dourados, 2015.

BOLLNOW, O. F. O homem e o Espaço. Tradução de Aloíso Leoni Schmid. Curitiba: Editora UFPR, 2008, 327 p.

BOTELHO, M. L. Colonialidade e forma da subjetividade moderna: a violência da identificação cultural na América Latina. Espaço e cultura, RJ, n. 34, p. 195-230, jul./dez. 2013.

BROSSEAU, M. Geografia e literatura. In: CORRÊA, Roberto Lobato; ROZENDAHL, Zeny (orgs.). Geografia Cultural: uma antologia (2). Rio de Janeiro: Eduerj, p. 265292, 2013.

BUTTIMER. A. Aprendendo o dinamismo do mundo vivido. In: CHRISTOFOLETTI, Antônio (org.). Perspectivas da Geografia. São Paulo: Difel, p. 165-193, 1982.

CARVALHAES, F. F. e et al. Territórios, Gerações \& Cultura: (Des)continuidades das Expressões de Gênero entre Lésbicas. Revista Latino-americana de Geografia e Gênero, v. 2, n. 1, p. 92-103, jan./jul. 2011.

CARVALHO SOBRINHO, H. ; SUESS, R. C. ; LEITE, C. M. C. . Lugar de vida e luta no meio rural de Formosa (Goiás - Brasil): Pré-assentamento Fartura/Miguel Caetano. Élisée - Revista de Geografia da Universidade Estadual de Goiás, v. 5, p. 102-117, 2016.

CARVALHO SOBRINHO, H. Geografa escolar e o lugar: a construção de conhecimentos no processo de ensinar/aprender geografia. Geosaberes, v. 9, n. 17, p. 117, jan/abr. 2018.

CARVALHO SOBRINHO, H.; SUESS, R. C.; DOURADO, M. V. Música e ensino de geografia: o estudo da Geografia de Goiás por meio de músicas com alunos do Ensino Médio em Formosa-GO. Revista Espaço e Geografia, v. 19, n. 2, 2016.

CASSIRER, E. A filosofia das formas simbólicas: primeira parte. A linguagem. São Paulo: Martins Fontes, 2001.

CASTRO, J. R. B. Paisagens e visões míticas, questões de gênero e a cidade no romance "Mar Morto", de Jorge Amado. Geograficidade, v. 5, n. 2, inverno 2015.

CLAVAL, P. Campos e perspectivas da Geografia Cultural. In: CORRÊA, R. L.; ROSENDAHL, Z. (org.). Geografia Cultural: um século (3). Rio de Janeiro: EdUERJ, p. 134-196, 2002.

CORRÊA, A. M. "Não acredito em deuses que não saibam dançar": a festa do candomblé, território encarnador da cultura. In: CORREAA, R. L.; ROZENDAHL, Z. (orgs.). Geografia Cultural: uma antologia (2). Rio de Janeiro: Eduerj, p. 203-218, 2013. 


\section{REVISTA ELETRÔNICA \\ DA GRADUAÇÃO/PÓS-GRADUAÇÃO EM EDUCAÇÃO UFG/REJ}

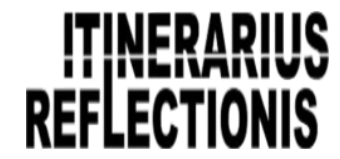

ISSN. 1807-9342

Volume 14, N. 2, 2018

CORRÊA, R. L. Monumentos, políticas e espaço. In: CORRÊA, Roberto Lobato; ROZENDAHL, Zeny (orgs.). Geografia Cultural: uma antologia (2). Rio de Janeiro: Eduerj, p. 73-90, 2013.

CORRÊA, R. L. Cultura, política, economia e espaço. Espaço e cultura, RJ, n. 35, p. 27-39, jan. jun. 2014.

CORRÊA, R. L. Espaço e simbolismo. In: CASTRO, I. E.; GOMES, P. C. C.;

CORREA, R. L. (orgs). Olhares geográficos: modos de ver e viver o espaço. Rio de Janeiro: Bertrand Brasil, p. 133-153, 2012.

CORREAA, R. L.; ROSENDAHL, Z. Cinema, música e espaço. Ed.UERJ, 2009.

CORREAA, R. L; ROZENDAHL, Z. Geografia cultural: apresentando uma antologia. In: CORREAA, Roberto Lobato; ROZENDAHL, Zeny (orgs.). Geografia Cultural: uma antologia (1). Rio de Janeiro: Eduerj, p. 219-237, 2012a.

. A geografia cultural brasileira: uma avaliação preliminar. In:

CORRÊA, R; ROZENDAHL, Z. (orgs.). Geografia Cultural: uma antologia (1). Rio de Janeiro: Eduerj, p. 219-237, 2012 b.

COSGROVE, D. A geografia está em toda parte: cultura e simbolismo nas paisagens humanas. In: CORRÊA, R. L; ROZENDAHL, Z. (orgs.). Geografia Cultural: uma antologia (1). Rio de Janeiro: Eduerj, p. 219-237, 2012.

COSTA, C. L.. A Presença e Ausência do Debate de Gênero na Geografia do Ensino Fundamental e Médio. Revista Latino-americana de Geografia e Gênero, Ponta Grossa, v. 2, n. 2, p. 76-84, ago./dez. 2011.

COSTA, M. H. B. V. Geografia cultural e cinema: práticas, teorias e métodos. In: CORREAA, Roberto Lobato; ROZENDAHL, Zeny (orgs.). Geografia Cultural: uma antologia (2). Rio de Janeiro: Eduerj, p. 247-265, 2013.

COSTA, M. H. B. V. Cidades e lugares culturais, espaços e geografias fílmicas: compondo imageticamente o lugar. Espaço e cultura, n. 36, p. 139-153, jul./dez. 2014.

COSTA, O. Memória e paisagem: em busca do simbólico dos lugares. Espaço e cultura, RJ, Edição comemorativa, p. 149-156, 2008.

DUNCAN, J. S. Após a guerra civil: reconstruindo a geografia cultural como heterotopia. In: CORREA,R. L; ROZENDAHL, Z. (orgs.). Geografia Cultural: uma antologia (1). Rio de Janeiro: Eduerj, p. 219-237, 2012.

FERRAZ, C. Bo. Geografia e paisagem - entre o olhar e o pensar. 2002. 380 p. Tese (Doutorado em Geografia). FFLCH/USP, SP, 2002.

FERREIRA, R. V. J.; FARIA, J. S. A literatura como potência problematizadora do lugar: imagens projetadas pelas crianças. Geograficidade, v. 02, n. especial, primavera 2012.

FREIRE, P. Pedagogia do oprimido. São Paulo: Paz e Terra, 2014.

FREIRE, P.; GUIMARÃES, S. Dialogando com a própria história. São Paulo: Paz e Terra, 2011.

FREMÓNT, A. A região, espaço vivido. Coimbra: Almedina, 1980, 220 p. 


\section{REVISTA ELETRÔNICA \\ DA GRADUAÇÃO/PÓS-GRADUAÇÃO EM EDUCAÇÃO \\ UFG/REJ}

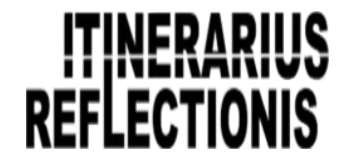

ISSN. 1807-9342

Volume 14, N. 2, 2018

FUINI, L. L. e et al.A música como instrumento para o ensino de geografia e seus conceitos fundamentais: pensando em propostas para o trabalho em sala de aula. Para onde!?, v. 6, n. 2, p. 206-216, jul. jul. 2012.

GIL FILHO, S. F. Espacialidades de conformação simbólica em geografia da religião: um ensaio epistemológico. Espaço e cultura, RJ, n. 32, p. 78-90, jul./dez. 2012.

GOMES, H.; NETO, A. T.; BARBOSA, A. S. (Org.). Geografia: Goiás-Tocantins. Goiânia: Editora UFG, 2004.

GOMES, P. C. C.; RIBEIRO, L. P. A produção de imagens para a pesquisa em Geografia. Espaço e Cultura, Rio de Janeiro, n. 33, p. 27-42, jan./jun. 2013.

HAESBAERT, R. Território, poesia e identidade. Espaço e cultura, RJ, n. 3, p.20-32, janeiro de 1997.

LANDO, F.. La Geografia Umanista: un'interpretazione. Rivista Geografica Italiana, Veneza-ITA, n. 119, p. 259-289, 2012.

LEITE, C. M. C. O lugar e a construção da identidade: os significados construídos por professores de Geografia do ensino fundamental. 2012. xvii, $222 \mathrm{f}$. Tese (Doutorado em Educação)—Universidade de Brasília, Brasília, 2012.

LEITE, C. M. C. O lugar e a construção da identidade: os significados construídos por professores de geografia do ensino fundamental. 222 f., 2012. Tese (doutorado em Geografia). Faculdade de Educação, Programa de pós-graduação em Educação, Universidade de Brasília, 2012.

LENZI, M. H. Das imagens, a ausência: aportes teóricos para o estudo das imagens da cidade na geografia. Geograficidade, número especial, p. 83-93, primavera 2012.

LÉVY, B. Humanistic Geography ou le pari humaniste de la géographie anglo-saxonne.

L'Espace Géographie, v. 10, n. 4, p. 301-303, 1981.

MARANDOLA JR., E. "Londrinas" invisíveis: percorrendo cidade imaginárias. 2003, 254 f. Monografia (Graduação em Geografia). Universidade Estadual de Londrina, 2003.

MARANDOLA JR., E.; GRATÃO, L. H. B. (orgs.). Geografia e Literatura: ensaios sobre geograficidade, poética e imaginação. Londrina, PR: Eduel, 2010.

MARANDOLA JR., E.; GRATÃO, L. H. B.. Do sonho à memória: Lívia de Oliveira e a Geografia Humanista no Brasil. Geografia, Londrina, v. 12, n. 2, jul./dez. 2003.

MARQUES, I. Imagear: o lugar, os viajantes e as imagens. Geograficidade, v. 2, Número especial, primavera 2012.

MELLO, J. B. F. Dos espaços da escuridão aos lugares de extrema luminosidade - o universo da estrela Marlene como palco e documento para a construção de conceitos geográficos. Tese (Doutorado em Geografia) - Instituto de Geociências, Universidade do Estado do Rio de Janeiro, 2000.

MELLO, J. B. F. O Rio de Janeiro dos compositores da música popular brasileira 1928/1991 - uma introdução à geografia humanística. Dissertação (Mestrado em Geografia) - Instituto de Geociências, Universidade Federal do Rio de Janeiro, 1991. 


\section{REVISTA ELETRÔNICA \\ DA GRADUAÇÃO/PÓS-GRADUAÇÃO EM EDUCAÇÃO UFG/REJ}

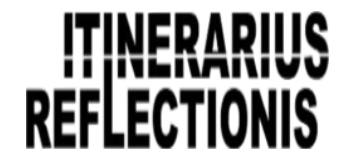

ISSN. 1807-9342

Volume 14, N. 2, 2018

MELLO, J. B. F. O Rio dos Símbolos Oficiais e Vernaculares. In: ROSENDAHL, Zeny; CORRÊA, R. L. (Orgs.). Espaço e Cultura: Pluralidade Temática. Rio de Janeiro: EdUERJ, 2008, v. , p. 173-186.

MELLO, J. B. F. Símbolos dos Lugares, dos Espaços e dos "Deslugares" Espaço e Cultura, v. 1, p. 167-174, 2008.

MELLO, J. B. F. A Geografia Humanística: a perspectiva da experiência vivida e uma crítica radical ao positivismo. Revista Brasileira de Geografia. Fundação Instituto Brasileiro de Geografia Estatística - IBGE. Rio de Janeiro, v.52, n. 4, p. 91-114, out/dez, 1990.

MONTEIRO, C. A. F. A Geografia no Brasil ao longo do século XX: um panorama. Borrador, AGB-São Paulo, n.4, p. 1-49, jul. 2002.

MOREIRA, M. F. Casa e família na Geografia: estratégias espaciais de mulheres semteto na construção do lar. Espaço e cultura, RJ, n. 34, p. 83-122, jul./Dez. 2013.

MOREIRA, R. Para onde vai o pensamento geográfico? Por uma epistemologia crítica. São Paulo: Contexto: 2014.

MOREIRA, T. A. Ensino de Geografia com o uso de filmes no Brasil. Revista do Departamento de Geografia, v. 23, p. 55-82, 2012.

NOVAES, A. R. Um Mapa do Tráfico no Livro Didático: Encontros e Desencontros entre Geografia Escolar e Cartografia Midiática. Geograficidade, v. 2, n. especial, p. 134-154, primavera de 2012.

OLIVEIRA, H. C. M. de et al. A música como recurso alternativo nas práticas educativas em Geografia: algumas reflexões. Caminhos de Geografia, n. 15, v. 8, 73 81, jun. 2015.

OLIVEIRA, L.. Lugares míticos. Geograficidade, v. 5, n. 2, p. 18-25, Inverno 2015.

PANITZ, L. M. Geografia e música: uma introdução ao tema. Biblio 3W, Barcelona, ES, v. 17, n. 978, maio 2012.

PANITZ, L. M. Por uma geografia da música: o espaço geográfico da música popular platina. 2010. 200 f. Dissertação (Mestrado em Geografia). Instituto de Geociências. Programa de Pós-Gradução em Geografia, Programa de Pós Graduação em Geografia, 2010.

ROSENDAHL, Z.. Espaço, política e religião. In: CORRÊA, R. L.; ROZENDAHL, Z. (orgs.). Geografia Cultural: uma antologia (2). Rio de Janeiro: Eduerj, p. 147-162, 2013.

ROSENDAHL, Z. Hierópolis: O Sagrado e o urbano. Rio de Janeiro: EdUERJ, 2009.

ROSENDAHL, Z. Os caminhos da construção teórica: ratificando as relações entre espaço e religião. In: CORRÊA, Roberto Lobato; ROZENDAHL, Zeny (orgs.).

Geografia Cultural: uma antologia (2). Rio de Janeiro: Eduerj, p. 103-118, 2013.

SILVA, F. C. Por uma geografia da lírica: representações do espaço na poesia de Carlos Drummond de Andrade (Sentimento do mundo, A rosa do povo e Menino 


\section{REVISTA ELETRÔNICA \\ DA GRADUAÇÃO/PÓS-GRADUAÇÃO EM EDUCAÇÃO \\ UFG/REJ}

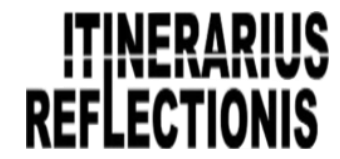

ISSN. 1807-9342

Volume 14, N. 2, 2018

antigo). 2014, 204 f. Dissertação (mestrado em Geografia Humana). Departamento de Geografia, Universidade de São Paulo, 2014.

SOUZA, C. R. P. Religião e política: o mundo evangélico e a geografia do voto.

Espaço e cultura, RJ, n. 37, p. 99-115, jan./jun. 2015.

SUESS, R. C. Geografia Humanista e ensino-aprendizagem: perspectivas em Formosa-GO. 2016. 171 f. Dissertação (Mestrado em Geografia). Instituto de Ciências Humanas, Departamento de Geografia, Programa de Pós-Graduação em Geografia, Universidade de Brasília, 2016.

;BEZERRA, R. G. Concepções de moradores e turistas do distrito de São Jorge - GO: uma reconstrução cultural. Revista Querubim - Universidade Federal Fluminense, v. 2, p. 123-129, 2013.

. Uma leitura do estado de Goiás (Brasil): elos entre música, território e lugar. Cuadernos de Geografîa - Revista Colombiana de Geografia, v. 25, p. 195-206, 2016.

. Lugar e Geografia Humanista: possibilidade de ensinar-aprender Geografia. In: Fórum NEPEG de Formação de Professores de Geografia, Caldas Novas, 2016. Anais... Goiânia: UFG, p. 726-733, 2016.

; ALMEIDA, S. A. O “lugar" de Goiás nas letras de músicas sertanejas: uma abordagem geográfica. Caminhos de Geografia - Universidade Federal de Uberlândia, v. 16, n. 54, jul. 2015.

; BEZERRA, R. G. O espaço do cerrado contado por meio de versos, estrofes e rimas: uma leitura realizada por meio da perspectiva do lugar. GeoUERJ Universidade do Estado do Rio de Janeiro, p. 329-353, 2015.

; BEZERRA, R. G.; CARVALHO, H. S. Percepção ambiental de diferentes atores sociais sobre o lago do Abreu em Formosa - GO. Holos - Instituto Federal do Rio Grande do Norte, v. 6, p. 241, 2014.

; CARVALHO, H. S.; BEZERRA, R. G. Geografia, cidade e lugar no processo de ensino e aprendizagem: um enfoque a partir da cidade de Formosa - GO. Itinerarius Reflectionis - Revista eletrônica em Educação - Universidade Federal de Goiás, v. 1, p. 1-13, 2014.

; LEITE, C. M. C. Estudar o lugar para compreender a si mesmo e o mundo: análise de uma experiência pedagógica em geografia desenvolvida com alunos do $6^{\circ}$ ano do ensino fundamental. Revista Brasileira de Educação em Geografia, v. 6, p. 74-98, 2016.

; LEITE, C. M. C. Paulo Freire e humanismo em educação: contribuições a partir de uma perspectiva geográfica. Geosaberes: revista de estudos geoeducacionais, Fortaleza, v. 8, n. 16, p. 94 - 105, set. 2017.

; CARVALHO SOBRINHO, H. ; BEZERRA, R. G. Educação no Campo: desafios e perspectivas de uma escola no campo localizada no Distrito Federal. Cadernos de Pesquisa - Universidade Federal do Maranhão, v. 21, p. 1-20, 2014 


\section{REVISTA ELETRÔNICA \\ DA GRADUAÇÃO/PÓS-GRADUAÇÃO EM EDUCAÇÃO \\ UFG/REJ}

\section{ITHEPAPIIS REFLECTIONIS}

ISSN. 1807-9342

Volume 14, N. 2, 2018

TUAN, Y-F. Espaço e Lugar: a perspectiva da experiência. Tradução de Lívia de Oliveira. Londrina, PR: Eduel, 2013a, 248 p.

VIGOTSKI, L. S. Pensamento e linguagem. Tradução de Jefferson Luiz Camargo; revisão técnica de José Cipolla Melo. 4ª ed. São Pau o: Martins Fontes, 2008.

WHITE, L. A.; DILLINGHAM, B. O conceito de cultura. Tradução Tereza Dias Carneiro. Rio de Janeiro: Contraponto, 2009, 127 p.

ZDEBSKYI, J. F.; MARANHÃO, E. M. A.; PEDRO, J. M. A histérica e as belas, recatadas e do lar: misoginia à Dilma Rousseff na concepção das mulheres como costelas e dos homens como cabeça da política brasileira. Espaço e cultura, n. 38, p. 225-250, jul./dez. 2015. 